\title{
Resective surgery for medically refractory epilepsy using intraoperative MRI and functional neuronavigation: the Erlangen experience of $\mathbf{4 1 5}$ patients
}

\author{
Karl Roessler, MD, PhD, ${ }^{1}$ Andrea Hofmann, ${ }^{1}$ Bjoern Sommer, MD, ${ }^{1}$ Peter Grummich, MD, ${ }^{1}$ \\ Roland Coras, MD, ${ }^{2}$ Burkard Sebastian Kasper, MD, PhD, ${ }^{3}$ Hajo M. Hamer, MD, MHBA, ${ }^{3}$ \\ Ingmar Blumcke, MD, PhD, ${ }^{2}$ Hermann Stefan, MD, PhD, ${ }^{3}$ Christopher Nimsky, MD, PhD, ${ }^{4}$ and \\ Michael Buchfelder, MD, PhD'1 \\ Departments of ${ }^{1}$ Neurosurgery, ${ }^{2}$ Neuropathology, and ${ }^{3}$ Neurology, Epilepsy Centre, University Hospital Erlangen; and \\ ${ }^{4}$ Department of Neurosurgery, University Hospital Marburg, Germany
}

\begin{abstract}
OBJECTIVE Intraoperative overestimation of resection volume in epilepsy surgery is a well-known problem that can lead to an unfavorable seizure outcome. Intraoperative MRI (iMRI) combined with neuronavigation may help surgeons avoid this pitfall and facilitate visualization and targeting of sometimes ill-defined heterogeneous lesions or epileptogenic zones and may increase the number of complete resections and improve seizure outcome.
\end{abstract}

METHODS To investigate this hypothesis, the authors conducted a retrospective clinical study of consecutive surgical procedures performed during a 10-year period for epilepsy in which they used neuronavigation combined with iMRI and functional imaging (functional MRI for speech and motor areas; diffusion tensor imaging for pyramidal, speech, and visual tracts; and magnetoencephalography and electrocorticography for spike detection). Altogether, there were 415 patients (192 female and 223 male, mean age 37.2 years; $41 \%$ left-sided lesions and $84.9 \%$ temporal epileptogenic zones). The mean preoperative duration of epilepsy was 17.5 years. The most common epilepsy-associated pathologies included hippocampal sclerosis $(n=146[35.2 \%])$, long-term epilepsy-associated tumor (LEAT) $(n=67[16.1 \%])$, cavernoma $(n=$ $45[10.8 \%])$, focal cortical dysplasia $(n=31[7.5 \%])$, and epilepsy caused by scar tissue $(n=23[5.5 \%])$.

RESULTS In 11.8\% $(n=49)$ of the surgeries, an intraoperative second-look surgery (SLS) after incomplete resection verified by iMRI had to be performed. Of those incomplete resections, LEATs were involved most often ( $40.8 \%$ of intraoperative SLSs, $29.9 \%$ of patients with LEAT). In addition, $37.5 \%$ (6 of 16) of patients in the diffuse glioma group and $12.9 \%$ of the patients with focal cortical dysplasia underwent an SLS. Moreover, iMRI provided additional advantages during implantation of grid, strip, and depth electrodes and enabled intraoperative correction of electrode position in $13.0 \%$ ( 3 of 23 ) of the cases. Altogether, an excellent seizure outcome (Engel Class I) was found in $72.7 \%$ of the patients during a mean follow-up of 36 months (range 3 months to 10.8 years). The greatest likelihood of an Engel Class I outcome was found in patients with cavernoma (83.7\%), hippocampal sclerosis $(78.8 \%)$, and LEAT (75.8\%). Operative revisions that resulted from infection occurred in $0.3 \%$ of the patients, from hematomas in $1.6 \%$, and from hydrocephalus in $0.8 \%$. Severe visual field defects were found in $5.2 \%$ of the patients, aphasia in $5.7 \%$, and hemiparesis in $2.7 \%$, and the total mortality rate was $0 \%$.

CONCLUSIONS Neuronavigation combined with iMRI was beneficial during surgical procedures for epilepsy and led to favorable seizure outcome with few specific complications. A significantly higher resection volume associated with a higher chance of favorable seizure outcome was found, especially in lesional epilepsy involving LEAT or diffuse glioma. http://thejns.org/doi/abs/10.3171/2015.12.FOCUS15554

KEY WORDS drug-resistant epilepsy; resective epilepsy surgery; intraoperative MRI; neuronavigation; functional MRI; seizure outcome; surgical complications 
$\mathrm{I}$ $\mathrm{N}$ lesional epilepsy surgery, the extent of resection is generally the key prognostic factor for seizure outcome. This tendency holds true particularly in cases in which clear borders are missing or the epileptogenic zone (EZ) exceeds the lesion itself, as is often the case in patients with focal cortical dysplasia (FCD). ${ }^{26,64}$ Surgically accessible pathologies associated with medically refractory epilepsy most often include hippocampal sclerosis (HS), long-term epilepsy-associated tumors (LEATs), cavernous malformations (CMs), or FCD, among others. ${ }^{25,43,62,64}$ Overall, treatment of these entities results in a favorable seizure outcome when they are completely resected. ${ }^{22,44,50,68,75}$ In addition, intrinsic epilepsy-associated tumors may have diffuse borders and may be located adjacent to motor or temporal speech areas. ${ }^{60,73,74,75} \mathrm{~A} \mathrm{CM}$ or FCD may have contact with deep structures such as speech or visual tracts. ${ }^{74,83}$ Thus, the use of intraoperative structural and diffusion tensor imaging (DTI) and neuronavigation can lead to increased resection volume and prevent postoperative neurological deterioration,,$^{51,60,70,72,85}$ which is why, in 2002, we began performing surgery on patients with surgically treatable epilepsy in an operating theater equipped with a high-field 1.5-T intraoperative MRI (iMRI) facility. In addition, for lesions near eloquent cortical brain areas or tracts, functional MRI (fMRI) and DTI may help surgeons to visualize eloquent cortex and fiber tracts preoperatively. ${ }^{61,72}$ These functional data can be integrated into intraoperative navigational MR images to decrease the rates of residual tumor and neurological complications. ${ }^{61}$ Early iMRI study groups demonstrated the principal practicability of epilepsy surgery performed in an MR operating suite. Apart from these early studies, however, convincing information from small case series demonstrating the advantages of iMRI for distinct epilepsy surgical procedures is still lacking..$^{12,13,51,85}$ To our knowledge, this is the first report on surgical and seizure outcome results in a large consecutive cohort of patients with epilepsy surgically treated using neuronavigation and iMRI. Our results demonstrate that there is a significant benefit of iMRI combined with neuronavigation, not for all operations but particularly for surgical procedures for lesional epilepsy.

\section{Methods}

\section{Preoperative Examination Protocol}

Altogether, 415 patients (192 female and 223 male; mean age 37.2 years [range 5-69 years]; 160 [41\%] leftsided lesions) suffering from medically refractory epilepsy were included in this retrospective investigation between August 2002 and April 2013. Epidemiological data are shown in Table 1. All patients underwent an extensive presurgical epilepsy protocol that consisted of video electroencephalographic monitoring, high-resolution 1.5- and 3-T MRI, neuropsychological testing, fMRI, Wada testing, PET, SPECT, and magnetoencephalography (MEG). ${ }^{76-78}$ The results of these investigations were discussed in an interdisciplinary conference, and a preliminary surgical treatment plan was established for patients eligible for resection. Preoperatively, 47 patients underwent fMRI or DTI of the speech, motor, and sensory cortical areas and tracts to determine the vicinity of their lesion in relation to these functionally eloquent areas, and the results were considered while determining the resection plan. For 20 patients, an MEG-detected spike focus was incorporated in the neuronavigation plan, and for 126 patients, intraoperative electrocorticography $(\mathrm{ECoG})$ was embedded into the resection plan.

\section{Preoperative Structural and Functional MRI, and Diffusion Tensor Imaging in the Operating Room}

We used a clinical whole-body 1.5-T MR scanner with echo planar imaging (Magnetom Sonata, Siemens Medical Solutions) equipped with a standard head coil for fMRI and DTI as previously described. ${ }^{36}$ The applied scan sequences included a T1-weighted 3D data set (magnetization-prepared rapid-acquisition gradient echo [MPRAGE]) sequence and an axial T2-weighted and a DTI sequence for tractography. The MPRAGE images were the basis of the registration and intraoperative orientation in neuronavigation. The applied activation protocols and stimulation paradigms for functional imaging to localize Broca and Wernicke cortical speech areas and verbal memory areas have been described in detail elsewhere. ${ }^{36,60,72}$ The local ethics committee of the University Erlangen-Nuremberg approved the use of iMRI, and signed informed consent was obtained from every patient.

\section{IMRI and Neuronavigation}

After acquisition of the initial iMRI for planning the neuronavigation and coregistration of functional data, a second iMRI was performed when the surgeon had the impression that complete resection of the lesion or resection of a sufficient extent of the hippocampus (at least $2-2.5 \mathrm{~cm}$ ) had been completed and planned to close the craniotomy. A third iMRI was performed after resection of the residual lesion or resection of an insufficiently resected hippocampus. Nimsky et al. ${ }^{57}$ have already given a detailed description of the intraoperative workflow they used in the iMRI suite (1.5-T iMRI; Magnetom Sonata Maestro Class, Siemens Healthcare).

The first iMRI scans included a T1-weighted MPRAGE sequence (TE $4.38 \mathrm{msec}$, TR $2020 \mathrm{msec}$, matrix size 128 $\times 128$ [interpolated to $256 \times 256$ ], field of view [FOV] 250 $\mathrm{mm}$, slice thickness $1 \mathrm{~mm}$, slab $16 \mathrm{~cm}$ ), T2-weighted coronal and transversal images (TE $98 \mathrm{msec}$, TR $6520 \mathrm{msec}$, matrix size $512 \times 307$, FOV $250 \mathrm{~mm}$, slice thickness 3 $\mathrm{mm}$ ), and a DTI sequence (TE $86 \mathrm{msec}$, TR $9200 \mathrm{msec}$, matrix size $128 \times 128$, FOV $240 \mathrm{~mm}$, slice thickness 3 $\mathrm{mm})$. The same scanning protocol was used for both preoperative and intraoperative MRI. While the patient was shifted back into the operating position, preoperative functional data and iMRI data were fused with the inceptive scans. The lesion or the hippocampus was segmented manually using the neuronavigation software (iPlan 2.6; BrainLAB AG), and trajectories to defined target points were calculated. After registration of functional data and current iMRI data, the data were transferred to an OPMI Pentero operation microscope (Zeiss) and displayed in the FOV intraoperatively. Lesion contours, contours of functional areas (areas at risk), and trajectories to target areas were projected to the patient's head and painted on the skin. Skin incision was adapted to this painting. During 
surgery, real-time 3D reconstructions of lesion contours and risk areas guided the resection and were visible to the surgeon during resection in different colors that corresponded to the depth of field.

\section{Intraoperative ECoG and Quantification of Resection}

For determination of the EZ in patients in whom the preoperative electroclinical findings revealed a larger EZ than the extent of the lesion (126 patients [30.4\%]), additional intraoperative ECoG was performed. Cortical strip, grid, or depth electrodes were placed on the cortex intraoperatively to define the epileptogenic areas in 23 patients. We used a combination of up to four 4- to 6-contact subdural strips, 4-contact depth electrodes for hippocampal and amygdala positioning, or 32-electrode subdural grids (Ad-Tech Medical Instrument Corporation and PMT/Permark Corporation) and an electrode rack that consisted of 16 surface electrodes. The correct anatomical position of the electrodes was confirmed by the first iMRI scans, and the position from the scans was measured by intraoperative neuronavigation. In all patients who underwent ECoG, a distinct resection area was defined from the ECoG measurements and defined as the resection volume for the neuronavigation-controlled resection (tailored resection). The total resection volume was confirmed during iMRI if this volume had been resected completely according to the preoperative and intraoperative MR images (in all cases, the fusion of preoperative and intraoperative MR images was performed), and a complete resection was confirmed if the preoperative lesion contours were within the resected lesion or the ECoG-defined tailored extended lesion volume.

\section{Surgical Technique}

The iMRI suite contains a 1.5-T Magnetom Sonata and a rotating operating table. Patients underwent surgery outside the 5-Gauss line; thus, normal instruments and a microscope were used for surgery. For intraoperative scanning, each patient was draped in a sterile manner and rotated into the scanner. Depending on the localization of the lesion, we performed either a standard craniotomy or a craniotomy modified by neuronavigation. Microsurgical techniques were used for lesionectomies or tailored resections according to intraoperative neuronavigation, with which we kept close to the displayed boundaries of suspected pathological tissue or ECoG-defined extended lesion volumes and spared normal brain. After we had the impression of complete resection, an iMRI scan was performed. If intraoperative MR images displayed remnant pathological tissue or incomplete resection of the designated EZ, we updated the neuronavigation data with iMRI data and continued surgery. A final MRI scan subsequently confirmed the maximum extent of resection before the closing procedure was performed. On average, every intraoperative scan lasted an additional 30 minutes, including time for sterile draping and 3 sequences (MPRAGE, T2-weighted axial, and DTI).

\section{Histological Diagnoses of the Resected Specimens and Electrode Implantation}

In addition to the main histological diagnoses of HS $(\mathrm{n}=146$ [35.2\%]), LEAT $(\mathrm{n}=67$ [16.1\%]), CM $(\mathrm{n}=45$ $[10.8 \%])$, FCD $(n=31[7.5 \%])$, and gliotic scar tissue (n $=23[5.5 \%]$ ), the pathological diagnoses of the remaining 103 patients included mild gliosis (35 patients), malignant glioma (WHO Grade III or IV; 16 patients), low-grade tumor (i.e., WHO Grade I or II meningioma or astrocytoma; 15 patients), and hypothalamic hamartoma (5 patients). ${ }^{76}$ Altogether, 23 patients underwent implantation of grid, strip, and depth electrodes for extraoperative monitoring without histological investigation.

\section{Definition of Postoperative Neurological Deterioration and Epilepsy Outcome}

Neurological outcome was evaluated and staged soon after surgery when the patient was discharged from the hospital and months after surgery in our outpatient center. In addition, seizure outcome was evaluated at the most recent follow-up visit. The most recent Engel classification was applied to categorize postsurgical seizure outcome. ${ }^{24}$ An excellent seizure outcome was defined as Engel Class I or Ia, whereas favorable seizure outcomes included Engel Classes I and II; Engel Classes III and IV were assigned to the poor seizure outcome category. The patients' most recent neurological and epilepsy outcome data were obtained from the follow-up examinations in the Neurological Epilepsy Centre at the University Hospital Erlangen or via telephone interviews. The neurological follow-up was completed for $88 \%$ (365) of the patients. Seizure outcome was available for $90.1 \%$ (374 of 415) of the patients. Statistical analysis was performed using parametric and nonparametric statistical tests (GraphPad Prism 5 software), and significance was indicated by a $\mathrm{p}$ value of $<0.05$.

\section{Results}

The demographic characteristics of this epilepsy surgery patient cohort are summarized in Table 1 . The most common lesions associated with epilepsy were categorized into the following 5 groups: HS ( $n=146$ [35.2\%]), LEAT $(n=67[16.1 \%]), \operatorname{CM}(n=45[10.8 \%]), \operatorname{FCD}(n=31$ [7.5\%]), and scar epilepsy $(n=23$ [5.5\%]) (Fig. 1). Other underlying pathologies such as gliotic epileptogenic lesions, diffuse gliomas, or other lesions were found in 103 patients $(24.8 \%)$. Temporal surgery was performed for $84.9 \%$ of the patients, and the other $15.1 \%$ underwent extratemporal surgery. Altogether, in $11.8 \%$ of the surgeries, an intraoperative second-look surgery resulting from incomplete resection verified by iMRI was performed. Forty-nine patients had incomplete resections detected during surgery with iMRI (Fig. 2), and $40.8 \%$ of these incomplete resections were detected during LEAT surgery. Concerning the specific groups, the highest percentage of secondlook surgeries was found within the diffuse glioma group (6 of 16 patients [37.5\%]). In the LEAT group, 29.9\% (20 of 67) of the patients underwent second-look surgery, and in the FCD group, $12.9 \%$ (4 of 31) underwent second-look surgery. The numbers of second-look surgeries in all the groups are provided in Fig. 2.

Moreover, iMRI provided additional advantages for 23 patients during the implantation of grid, strip, and depth electrodes (Table 2), the positions of which were corrected 
TABLE 1. Demographic characteristics of patients in the epilepsy surgery cohort

\begin{tabular}{|c|c|}
\hline Demographic & Value \\
\hline No. of patients & 415 \\
\hline \multicolumn{2}{|l|}{ Age (yrs) } \\
\hline Mean & 37.2 \\
\hline Range & $5-69$ \\
\hline \multicolumn{2}{|l|}{ Sex (no.) } \\
\hline Male & 223 \\
\hline Female & 192 \\
\hline \multicolumn{2}{|l|}{ Site of resection (\%) } \\
\hline Right & 50 \\
\hline Left & 41 \\
\hline Temporal & 84.9 \\
\hline Extratemporal & 15.1 \\
\hline \multicolumn{2}{|l|}{ Epilepsy duration } \\
\hline Mean & 17.5 yrs \\
\hline Range & $1 \mathrm{mo}$ to $55 \mathrm{yrs}$ \\
\hline \multicolumn{2}{|l|}{ Diagnosis (no. [\%]) } \\
\hline HS & $146(35.2)$ \\
\hline LEAT (GG, DNET) & $67(16.1)$ \\
\hline FCD & $31(7.5)$ \\
\hline $\mathrm{CM}$ & $45(10.8)$ \\
\hline Scar tissue & $23(5.6)$ \\
\hline $\begin{array}{l}\text { Others (diffuse tumor, gliosis, AVM, hamar- } \\
\text { toma, electrode repositioning) }\end{array}$ & $103(24.8)$ \\
\hline $\begin{array}{l}\text { iMRI-detected incomplete-resection rate (no. [\% } \\
\text { of procedures]) }\end{array}$ & 49 (11.8) \\
\hline \multicolumn{2}{|l|}{ Second-look surgery (no./total no. [\%]) } \\
\hline HS & $8 / 146(5.5)$ \\
\hline LEAT & 20/67 (29.9) \\
\hline $\mathrm{CM}$ & $3 / 45(6.7)$ \\
\hline FCD & 4/31 (12.9) \\
\hline Scar epilepsy & $2 / 23(8.7)$ \\
\hline Gliosis & $3 / 35(8.6)$ \\
\hline Diffuse glioma & 6/16 (37.5) \\
\hline Electrode repositioning & $3 / 23(13.0)$ \\
\hline \multicolumn{2}{|l|}{ General seizure outcome } \\
\hline Engel Class I & $272(72.7)$ \\
\hline Engel Class la & $222(59.4)$ \\
\hline Engel Class II & $43(11.5)$ \\
\hline Engel Class III & $37(9.9)$ \\
\hline Engel Class IV & $22(5.9)$ \\
\hline \multicolumn{2}{|l|}{ Follow-up time } \\
\hline Mean & 36 mos \\
\hline Range & 3 mos to $10.8 \mathrm{yrs}$ \\
\hline
\end{tabular}

$\mathrm{AVM}=$ arteriovenous malformation; $\mathrm{DNET}=$ dysembryoplastic neuroepithelial tumor; $\mathrm{GG}=$ ganglioglioma.

intraoperatively in $13.0 \%$ ( 3 of 23 ) of the patients. In patients with an LEAT, the often ill-defined tumor borders were identified clearly during iMRI scanning, especially when T2-weighted images were used. Similarly, remnant hemosiderotic rims after surgery for CMs or residuals in cases of diffuse glioma or gliotic tissue were identified successfully using iMRI. During surgery for HS, the exact amount of hippocampal tissue resected was defined by intraoperative scanning (mean $2.6 \mathrm{~cm}$ [146 patients]) and corrected in $16.3 \%$ of the surgeries. During resection of FCDs, the planned resection volume defined by MRI and invasive grid monitoring often exceeded the extent of the morphological lesion. In such cases, the resection plan included electrode positions, which were defined as part of the EZ by extraoperative monitoring.

In summary, an excellent postoperative seizure outcome (Engel Class I) was found in $72.7 \%$ (272 of 374 with completed follow-up) of the patients during a mean follow-up of 36 months (range 3 months to 10.8 years). In $59.4 \%$ (222) of the patients, no seizures during the postoperative course were documented (Engel Class Ia) (Table 1). The greatest likelihood of an Engel Class I outcome was found after surgery for CM (83.7\%), HS (78.8\%), or LEAT (75.8\%) (Fig. 3). Operative revisions that resulted from empyema occurred in $0.3 \%$ and from postoperative hematoma in $1.6 \%$ of the patients. Postoperative hydrocephalus occurred in $0.8 \%$ of the patients. Severe visual field deficits (more than one-quarter loss in vision) were found in $5.2 \%$ of the patients, and loss of less than onequarter occurred in $27.2 \%$. A $5.7 \%$ rate of postoperative aphasia was found. More severe complications such as hemiparesis occurred in $2.7 \%$ of the patients. No deaths occurred in this series (Table 3). In general, age, sex, hemisphere undergoing surgery, and duration of epilepsy of the patients did not have any significant effect on seizure outcomes in this cohort.

\section{Discussion}

\section{Summary of Findings}

We performed a retrospective study of 415 patients treated surgically for medically intractable epilepsy in which an iMRI suite (Fig. 4) and neuronavigation were used. In $11.8 \%$ of the surgeries, an intraoperative second-look surgery was performed because of incomplete resection verified by iMRI. Within a broad spectrum of involved pathologies (HS, LEAT, CM, FCD, scar epilepsy, and diffuse glioma), the patients who underwent resection of an LEAT or diffuse glioma had significantly higher intraoperative second-look surgery rates (29 of 67 [43.3\%] and 6 of 16 [37.5\%], respectively) than patients with other pathologies. The considerably high percentage of excellent Engel Class I seizure outcomes in $72.7 \%$ (272 of 374) of the patients during a mean follow-up of 36 months might be associated with the use of iMRI in this patient cohort. The highest numbers of Engel Class I outcomes were found in patients treated surgically for CM (83.7\%), HS (78.8\%), or LEAT (75.8\%). Typical specific complications of epilepsy surgery, such as hemianopia (5.2\%), dysphasia (5.7\%), or hemiparesis (2.7\%), were rare, although $84.9 \%$ of the patients underwent temporal resection. The inclusion of functional imaging (motor and speech fMRI and DTI for pyramidal, speech, and visual tracts) in the surgical navigation plan may be the reason for such a low neurological complication rate. 

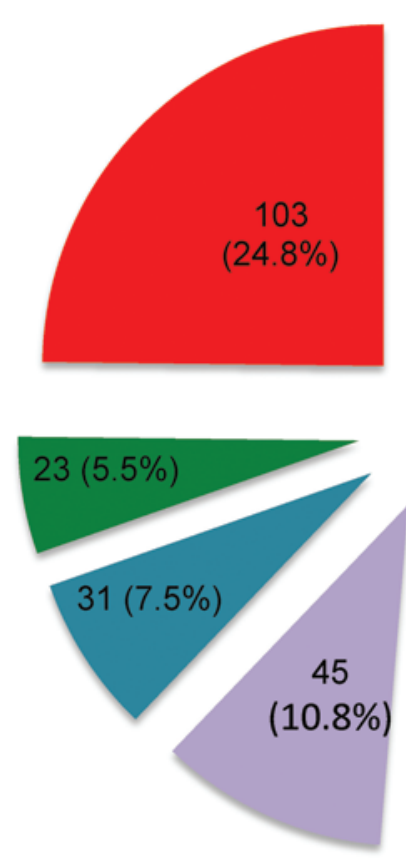

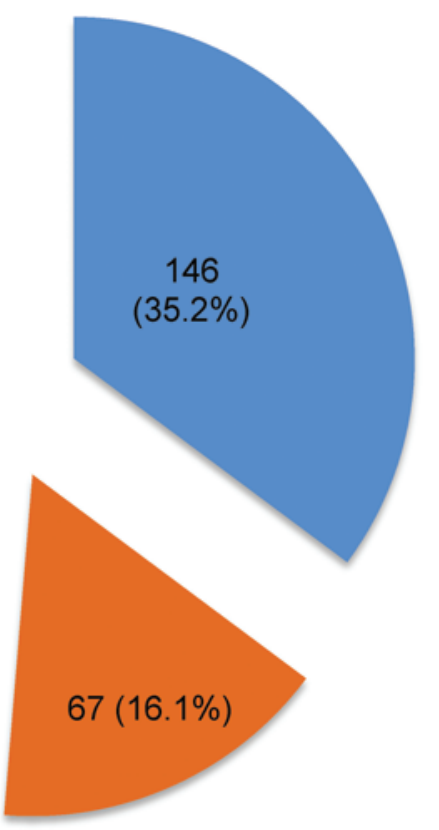

- Hippocampal sclerosis

- LEAT

= Cavernous malformation

- Focal cortical Dysplasia

- Scar Tissue

ather

FIG. 1. Main diagnoses in 415 patients suffering from intractable epilepsy and surgically treated using 1.5-T iMRI and functional neuronavigation.

\section{MRI Resection Control and Intraoperative Functional Neuronavigation}

First a low-field and then a high-field iMRI facility was established by the Erlangen iMRI study group nearly 2 decades ago. ${ }^{12-14,27,28,56,57,79}$ This facility was mainly used for glioma surgery and pituitary surgery, and also for epilepsy surgery. ${ }^{14,27,56}$ Early results of epilepsy surgeries here demonstrated that low-field iMRI in lesional epilepsy led to an increase in complete resections of epileptogenic lesions from $73 \%$ to $87 \% .^{12}$ Because of these encouraging early findings, all surgical procedures for epilepsy performed at the Erlangen Clinic from that time on were carried out using the newly installed high-field iMRI system, and this system was combined with neuronavigation in 2002 . Thus, the reported results represent comprehensive experience gained during epilepsy surgeries using this highfield system between 2002 and 2013 with 415 patients.

\section{Residual Lesions and Second-Look Surgeries}

The focus of this retrospective study with patients surgically treated for medically intractable epilepsy within a well-established epilepsy surgery program at the Erlangen University Hospital was centered on the frequency of second-look surgeries according to the different enti-

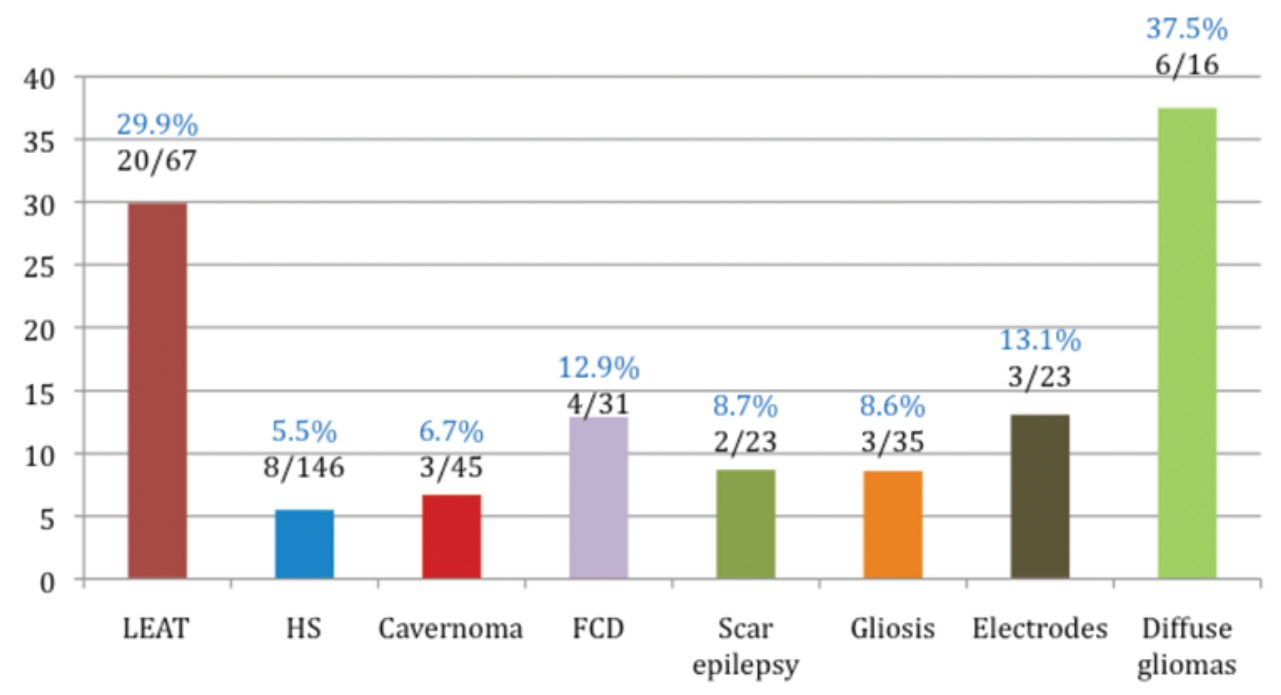

FIG. 2. Diagnoses in 49 patients who underwent intraoperative second-look surgery as a result of residual tissue planned for resection. Most of these surgeries (40.8\%) were performed on patients with an LEAT. The numbers indicate second-look surgeries of the total number of the specific diagnosis. In addition, the percentage of patients within each specific pathology group who underwent second-look surgery is shown. 
TABLE 2. Advantages of iMRI and neuronavigation for lesional and nonlesional epilepsy surgery

\begin{tabular}{|c|c|}
\hline Lesional Epilepsy & Nonlesional Epilepsy \\
\hline Planning of location \& extent of skin incision, craniotomy, \& dural opening & $\begin{array}{l}\text { Implementation of preop PET/MEG data into resection planning via image } \\
\text { fusion }\end{array}$ \\
\hline $\begin{array}{l}\text { Segmentation of lesion \& surrounding epileptogenic tissue (e.g., hemosid- } \\
\text { erotic rim in a CM) }\end{array}$ & $\begin{array}{l}\text { Verification of resected PET/MEG foci w/ iMRI during op (e.g., ganglio- } \\
\text { glioma, FCD) }\end{array}$ \\
\hline Planning of the trajectories for atraumatic targeting of deep-seated lesions & $\begin{array}{l}\text { Verification of preplanned electrode position during electrode implantation } \\
\quad \& \text { intraop correction of electrode malposition }\end{array}$ \\
\hline $\begin{array}{l}\text { Outlining of lesion borders (e.g., in ganglioglioma resection); implementa- } \\
\text { tion of functional imaging (fMRI/DTI) data for sparing of eloquent tissue }\end{array}$ & $\begin{array}{l}\text { Implementation of EEG data from invasive monitoring into the resection } \\
\text { approach; implementation of functional imaging (fMRI/DTI) data for } \\
\text { sparing of eloquent tissue }\end{array}$ \\
\hline $\begin{array}{l}\text { Intraop outlining of residual lesions \& resection during the same op } \\
\text { (intraop second-look surgery) }\end{array}$ & $\begin{array}{l}\text { Intraop comparison of preplanned resection target (EZ) w/ resection } \\
\text { extension during op; intraop second-look surgery w/ further resection }\end{array}$ \\
\hline
\end{tabular}

EEG = electroencephalography.

ties treated. Concerning the histological diagnoses of the resected lesions, the surgically treated patients most frequently suffered from HS $(n=146[35.2 \%])$, LEAT $(n=67$ [16.1\%]), CM ( $n=45$ [10.8\%]), FCD $(n=31$ [7.5\%]), or scar epilepsy $(n=23[5.5 \%])$, similarly to other reported large cohorts of surgically treated patients with epilepsy. ${ }^{19,23,40,64}$ During this period, the number of temporal lobe surgeries declined and the number of extratemporal resections increased, but not significantly. Similar findings have been reported in the literature. ${ }^{47}$ Nevertheless, temporal lobe surgeries were performed most often in this series $(84.9 \%$ of all patients), as expected. The mean duration of epilepsy in these patients was 17.5 years (range 1 month to 55 years), which is not surprising and has been reported frequently in large series. ${ }^{23}$

The overall probability of an intraoperative secondlook surgical intervention throughout all the interventions for these patients was found to be $11.8 \%$. It is interesting to note that there were distinct pathologies that resulted in a significantly higher proportion of second-look interventions; most significantly, $40.8 \%$ of those in the second-look surgery group were undergoing surgery for an $\operatorname{LEAT}^{10,81}$ (mainly involving gangliogliomas or dysembryoplastic tumors). Altogether, 29.9\% of the patients with an LEAT had an intraoperative need for additional resection, although the surgeon had the impression that the lesion had been resected totally before intraoperative scanning. According to iMRI, residual tumor was visualized and resected totally in most of these cases within the same surgery. For this reason, patients in this cohort with an LEAT were found to have an excellent long-term seizure outcome (76.9\% had an Engel Class I result). In comparison with those found in the literature, our results match with the best reported results (Engel Class I seizure outcomes between $46.3 \%$ and $85.7 \%$ in those who underwent surgery for an LEAT). ${ }^{3,18,32}$, $33,41,45,46,48,53,63,64,82$

As expected, in the few patients with diffuse gliomas treated for refractory epilepsy (16 of 415 patients), a high percentage (37.5\% [6 of 16]) underwent second-look surgery because of the diffuse borders of such lesions. All other entities for which intraoperative second-look interventions were performed as a result of iMRI detecting an

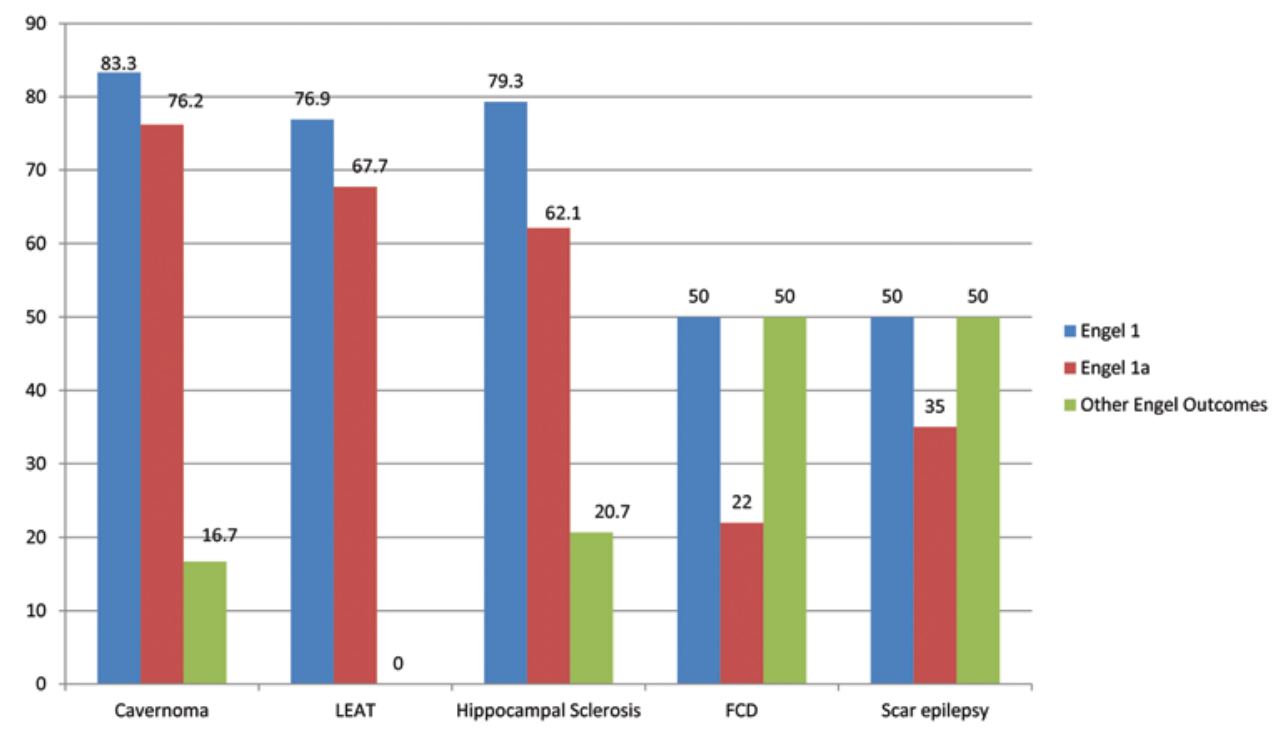

FIG. 3. Seizure outcomes within each different pathology group after surgery using iMRI and neuronavigation (the percentages are similar to those in seizure-free patients). 
TABLE 3. Complications after surgical procedures for epilepsy performed with iMRI and neuronavigation

\begin{tabular}{lcc}
\hline \multirow{2}{*}{ Complication } & \multicolumn{2}{c}{ Complication Rate (\%) } \\
\cline { 2 - 3 } & Erlangen Series & Literature \\
\hline Neurological & & \\
\hline Visual fields deficit & 27.1 & $46-64$ \\
\hline More than one-quarter & 5.2 & $7-11.1$ \\
\hline Memory deficit & 15.9 & $16-55$ \\
\hline Psychiatric abnormality & 6.6 & $7.8-39$ \\
\hline Dysphasia & 5.7 & $1.7-7.7$ \\
\hline Cranial nerve deficit & 4.1 & $2.5-3.2$ \\
\hline Hemiparesis & 2.7 & $0.9-5.1$ \\
\hline Death & 0 & $0.4-1.4$ \\
\hline General & & \\
\hline Hydrocephalus & 0.8 & 0.7 \\
\hline Hematoma & 1.6 & 1.4 \\
\hline Empyema & 0.3 & 1.4 \\
\hline
\end{tabular}

overlooked residual lesion or insufficient resection length of the hippocampus (defined as less than $2.0 \mathrm{~cm}$ ) comprised only a small fraction (between 16.3\% [hippocampus re-resection] and $4.1 \%$ [scar epilepsy]) of the secondlook surgery group. In $6.1 \%$ of this cohort, in patients who had electrode implantations, a correction of electrode position was performed intraoperatively as a consequence of the intraoperative MR images.

In summary, in concordance with a former investigation of our iMRI study group using low-field MRI, in which the rate of re-interventions resulting from insufficient resection was $14 \%$, a very similar result was found in the current study with a 1.5 -T high-field system. ${ }^{12}$ To our knowledge, there have been no reports of such high investigated-patient numbers in a study on epilepsy surgery using iMRI for comparison.

\section{Seizure Outcomes From Different Pathological Entities}

The seizure outcomes in our group of patients with CM were found to be extraordinary, with $83.3 \%$ Engel Class I and $76.2 \%$ Engel Class Ia (totally seizure free) outcomes. However, in lesional epilepsy and especially after CM re- section in patients with epilepsy, outcomes are generally reported to be favorable, with rates of Engel Class I outcomes of $65 \%-86 \%$ in the literature. ${ }^{4,9,15,21,29,64,80,84,87,88} \mathrm{Nev}$ ertheless, the CM seizure outcome results in the current study are among the top results reported in the literature. The rationale of these optimal results could be that we also performed resection of the hemosiderotic rim in nearly all patients with $\mathrm{CM}$ within the underlying study, as reported earlier. ${ }^{74}$ Although this strategy is controversial according to the current literature, our experience indicates that total resection of the CM and the hemosiderotic rim seems to optimize the seizure outcome. ${ }^{74}$

The seizure outcomes of patients who underwent resection for HS were found also to be optimal, with a rate of $79.3 \%$ of patients reaching Engel Class I during a mean follow-up of 36 months (range 3 months to 10.8 years). Following the discussion about the extent of hippocampal removal in patients with HS, there seems to be no difference in outcomes when resections are between 2.5 and $3.5 \mathrm{~cm} .{ }^{69}$ However, resection of less than $2 \mathrm{~cm}$ seems to diminish the result considerably ${ }^{67}$ In this respect, the intraoperative enlargement of resection volume in patients with HS in 5.5\% (8 of 146) of the patients in this series as a result of an unsatisfactory result from iMRI may also have contributed to the improvement in seizure outcomes (Fig. 2). Either way, with $79.3 \%$ of patients with an Engel Class I outcome, the result is also among the best results ever reported in the literature (Engel Class I outcomes in the literature are between $66 \%$ and $89 \%$ ). ${ }^{2,8,23,42,52,58}$

In general, patients suffering from seizures as a result of FCD or scar tissue after trauma or surgery have had lower rates of seizure outcome success after resection. . $^{1,5,17,49,59}$ It is unfortunate that the use of iMRI and neuronavigation did not seem to influence the seizure outcome in this patient group positively, as determined by retrospective analysis; an Engel Class I outcome in only $50 \%$ of these patients in the current study requires significant improvement, although for $12.9 \%$ of the patients with FCD and $8.9 \%$ of the patients with scar epilepsy, second-look surgery enlarged the resection volume (Fig. 2). This goal of enhanced seizure outcome after resection may be reached only by the application of new diagnostic methods and advanced surgical techniques in addition to iMRI and neuronavigation, as stated in a recent review paper. ${ }^{37}$

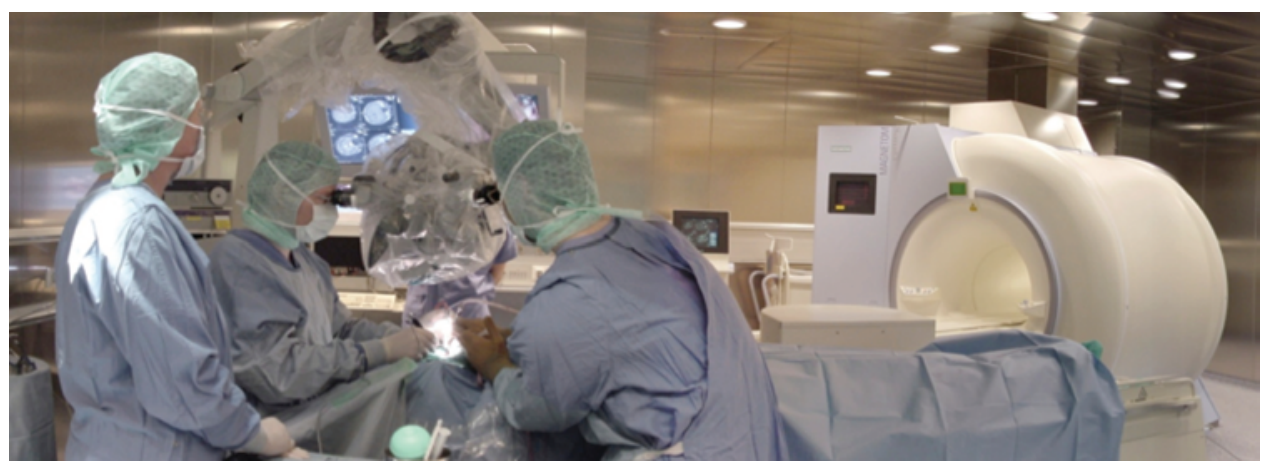

FIG. 4. The iMRI suite containing the 1.5-T Magnetom Sonata and a rotatable operating table. The patient undergoes surgery outside the 5-Gauss line; thus, normal instruments and a microscope can be used for surgery. For intraoperative scanning, the patient is draped in a sterile manner and rotated into the Magnetom. 


\section{General and Neurological Complications}

Compared with the reported complications during surgical procedures for epilepsy, the observed general and neurological complications in this study were considerably low (Table 3). ${ }^{6,7,11,31,34,38,54,65,66,86}$ It is remarkable that severe visual field deterioration (loss of more than one-quarter) was found in only $5.2 \%$ of the patients, which is much lower than rates in the literature. This outcome might have its origin in the inclusion of functional images of the visual tracts in many patients.

\section{Limitations of the Study}

Important limitations of our study are the lack of prospective, randomized controlled data that compare surgeries of epileptogenic lesions with and without using iMRI combined with neuronavigation and the lack of a control group for comparison. As an alternative to iMRI and neuronavigation, especially when combined with functional data, awake craniotomy may serve as an alternative as a state-of-the-art procedure with that has been used extensively for the identification of eloquent brain areas and the avoidance of postsurgical deficits. ${ }^{16,39}$ In addition, intraoperative electrophysiological and neurological monitoring using cortical and tract stimulation are available as stateof-the-art methods for avoiding postoperative deficits, even in the setting of iMRI. ${ }^{55,71}$ Such techniques were not used for the patients reported here. Nevertheless, our study group has validated this multimodal neuronavigation approach and integration of fMRI and DTI within conventional surgery in many studies performed during the last decade. ${ }^{30,35,36}$ Another problem concerning the use of neuronavigation and preoperative functional data during surgery is volumetric brain deformation and intraoperative loss of cerebrospinal fluid (brain shift), which diminish the accuracy of the depicted eloquent brain areas and fiber tracts. In our study, we took into account brain structure translocation and performed iMRI updates with new acquisition of navigation data and reassignment of residual pathological tissue using navigation-planning software. In all of our patients in whom resection was performed, we were able to remove remnant tissue completely when it was not located within functional areas. Intraoperative ultrasound combined with neuronavigation may also have been used to correct for brain shift during surgery, but the structural resolution was not comparable with that with the use of MRI. ${ }^{20}$ Because of the lack of availability of a high-end intraoperative ultrasound system combined with neuronavigation in our center, we were not able to compare the advantages of such a system over iMRI in epilepsy surgery.

\section{Conclusions}

Using 1.5-T iMRI seems to confer considerable advantages in epilepsy surgery. Particularly in cases in which the borders of the lesion are not clearly visible during surgery, an intraoperative MR image enables the exact definition of residual lesional tissue for second-look resection during the same procedure. Especially in lesional cases, this protocol may lead to a better seizure outcome, as already demonstrated in the literature for complete resections. ${ }^{26}$
This advantage was found to be especially prominent during surgery for LEATs $(40.8 \%$ of the patients who underwent second-look surgery in this study; Fig. 2), during which $29.9 \%$ (20 of 67 ) of the patients required secondlook surgery to resect the tumor completely. However, intraoperative imaging also offered patients suffering from HS the chance to optimize the extent of resection, and immediate correction of malposition was possible for patients who were selected for implantation of electrodes. In FCD or scar epilepsy cases, a convincing advantage was not found. In addition, the combination with neuronavigation and functional images in the investigated patient cohort seemed to have contributed to a low rate of severe complications (Table 3). We did not observe any adverse effects with the use of iMRI in epilepsy surgery, and it is notable that there were no increased infection rates.

\section{References}

1. Alexandre V Jr, Walz R, Bianchin MM, Velasco TR, TerraBustamante VC, Wichert-Ana L, et al: Seizure outcome after surgery for epilepsy due to focal cortical dysplastic lesions. Seizure 15:420-427, 2006

2. Aull-Watschinger S, Pataraia E, Baumgartner C: Sexual auras: predominance of epileptic activity within the mesial temporal lobe. Epilepsy Behav 12:124-127, 2008

3. Bauer R, Dobesberger J, Unterhofer C, Unterberger I, Walser G, Bauer G, et al: Outcome of adult patients with temporal lobe tumours and medically refractory focal epilepsy. Acta Neurochir (Wien) 149:1211-1217, 2007

4. Baumann CR, Acciarri N, Bertalanffy H, Devinsky O, Elger CE, Lo Russo G, et al: Seizure outcome after resection of supratentorial cavernous malformations: a study of 168 patients. Epilepsia 48:559-563, 2007

5. Bautista JF, Foldvary-Schaefer N, Bingaman WE, Lüders HO: Focal cortical dysplasia and intractable epilepsy in adults: clinical, EEG, imaging, and surgical features. Epilepsy Res 55:131-136, 2003

6. Behrens E, Schramm J, Zentner J, König R: Surgical and neurological complications in a series of 708 epilepsy surgery procedures. Neurosurgery 41:1-10, 1997

7. Beisse F, Lagrèze WA, Schmitz J, Schulze-Bonhage A: [Visual field defects after epilepsy surgery: implications for driving license tenure.] Ophthalmologe 111:942-947, 2014 (Ger)

8. Berkovic SF, McIntosh AM, Kalnins RM, Jackson GD, Fabinyi GC, Brazenor GA, et al: Preoperative MRI predicts outcome of temporal lobectomy: an actuarial analysis. Neurology 45:1358-1363, 1995

9. Bernotas G, Rastenyte D, Deltuva V, Matukevicius A, Jaskeviciene V, Tamasauskas A: Cavernous angiomas: an uncontrolled clinical study of 87 surgically treated patients. Medicina (Kaunas) 45:21-28, 2009

10. Blumcke I, Aronica E, Urbach H, Alexopoulos A, GonzalezMartinez JA: A neuropathology-based approach to epilepsy surgery in brain tumors and proposal for a new terminology use for long-term epilepsy-associated brain tumors. Acta Neuropathol 128:39-54, 2014

11. Blumer D, Wakhlu S, Davies K, Hermann B: Psychiatric outcome of temporal lobectomy for epilepsy: incidence and treatment of psychiatric complications. Epilepsia 39:478486, 1998

12. Buchfelder M, Fahlbusch R, Ganslandt O, Stefan H, Nimsky $\mathrm{C}$ : Use of intraoperative magnetic resonance imaging in tailored temporal lobe surgeries for epilepsy. Epilepsia 43:864-873, 2002

13. Buchfelder M, Ganslandt O, Fahlbusch R, Nimsky C: 
Intraoperative magnetic resonance imaging in epilepsy surgery. J Magn Reson Imaging 12:547-555, 2000

14. Buchfelder M, Nimsky C: Intraoperative low-field MR imaging in epilepsy surgery. Arq Neuropsiquiatr 61 (Suppl 1):115-122, 2003

15. Casazza M, Broggi G, Franzini A, Avanzini G, Spreafico $\mathrm{R}$, Bracchi M, et al: Supratentorial cavernous angiomas and epileptic seizures: preoperative course and postoperative outcome. Neurosurgery 39:26-34, 1996

16. Chang EF, Wang DD, Perry DW, Barbaro NM, Berger MS: Homotopic organization of essential language sites in right and bilateral cerebral hemispheric dominance. J Neurosurg 114:893-902, 2011

17. Chassoux F, Devaux B, Landré E, Turak B, Nataf F, Varlet $\mathrm{P}$, et al: Stereoelectroencephalography in focal cortical dysplasia: a 3D approach to delineating the dysplastic cortex. Brain 123:1733-1751, 2000

18. Choi JY, Chang JW, Park YG, Kim TS, Lee BI, Chung SS: A retrospective study of the clinical outcomes and significant variables in the surgical treatment of temporal lobe tumor associated with intractable seizures. Stereotact Funct Neurosurg 82:35-42, 2004

19. Clusmann H, Kral T, Fackeldey E, Blümcke I, Helmstaedter $\mathrm{C}$, von Oertzen J, et al: Lesional mesial temporal lobe epilepsy and limited resections: prognostic factors and outcome. J Neurol Neurosurg Psychiatry 75:1589-1596, 2004

20. Coburger J, König RW, Scheuerle A, Engelke J, Hlavac M, Thal DR, et al: Navigated high frequency ultrasound: description of technique and clinical comparison with conventional intracranial ultrasound. World Neurosurg 82:366-375, 2014

21. Cohen DS, Zubay GP, Goodman RR: Seizure outcome after lesionectomy for cavernous malformations. J Neurosurg 83:237-242, 1995

22. Elkommos S, Richardson MP, Schoene-Bake JC, Marson A, Elger C, Weber B, et al: Presurgical entorhinal cortex volume and postoperative seizure outcome in temporal lobe epilepsy. Lancet 385 (Suppl 1):S34, 2015

23. Elsharkawy AE, Alabbasi AH, Pannek H, Oppel F, Schulz $\mathrm{R}$, Hoppe M, et al: Long-term outcome after temporal lobe epilepsy surgery in 434 consecutive adult patients. $\mathbf{J}$ Neurosurg 110:1135-1146, 2009

24. Engel J Jr: Classification of epileptic disorders. Epilepsia 42:316, 2001

25. Englot DJ, Berger MS, Barbaro NM, Chang EF: Factors associated with seizure freedom in the surgical resection of glioneuronal tumors. Epilepsia 53:51-57, 2012

26. Englot DJ, Han SJ, Berger MS, Barbaro NM, Chang EF: Extent of surgical resection predicts seizure freedom in lowgrade temporal lobe brain tumors. Neurosurgery 70:921928, 2012

27. Fahlbusch R, Ganslandt O, Buchfelder M, Schott W, Nimsky $\mathrm{C}$ : Intraoperative magnetic resonance imaging during transsphenoidal surgery. J Neurosurg 95:381-390, 2001

28. Fahlbusch R, Ganslandt O, Nimsky C: Intraoperative imaging with open magnetic resonance imaging and neuronavigation. Childs Nerv Syst 16:829-831, 2000

29. Fernández S, Miró J, Falip M, Coello A, Plans G, Castañer S, et al: Surgical versus conservative treatment in patients with cerebral cavernomas and non refractory epilepsy. Seizure 21:785-788, 2012

30. Gasser T, Ganslandt O, Sandalcioglu E, Stolke D, Fahlbusch R, Nimsky C: Intraoperative functional MRI: implementation and preliminary experience. Neuroimage 26:685-693, 2005

31. Georgiadis I, Kapsalaki EZ, Fountas KN: Temporal lobe resective surgery for medically intractable epilepsy: a review of complications and side effects. Epilepsy Res Treat 2013:752195, 2013
32. Giulioni M, Marucci G, Martinoni M, Volpi L, Riguzzi P, Marliani AF, et al: Seizure outcome in surgically treated drug-resistant mesial temporal lobe epilepsy based on the recent histopathological classifications. J Neurosurg 119:37-47, 2013

33. Giulioni M, Rubboli G, Marucci G, Martinoni M, Volpi L, Michelucci R, et al: Seizure outcome of epilepsy surgery in focal epilepsies associated with temporomesial glioneuronal tumors: lesionectomy compared with tailored resection. J Neurosurg 111:1275-1282, 2009

34. Gleissner U, Helmstaedter C, Schramm J, Elger CE: Memory outcome after selective amygdalohippocampectomy in patients with temporal lobe epilepsy: one-year follow-up. Epilepsia 45:960-962, 2004

35. Grummich P, Nimsky C, Fahlbusch R, Ganslandt O: Observation of unaveraged giant MEG activity from language areas during speech tasks in patients harboring brain lesions very close to essential language areas: expression of brain plasticity in language processing networks? Neurosci Lett 380:143-148, 2005

36. Grummich P, Nimsky C, Pauli E, Buchfelder M, Ganslandt $\mathrm{O}$ : Combining fMRI and MEG increases the reliability of presurgical language localization: a clinical study on the difference between and congruence of both modalities. Neuroimage 32:1793-1803, 2006

37. Guerrini R, Duchowny M, Jayakar P, Krsek P, Kahane P, Tassi L, et al: Diagnostic methods and treatment options for focal cortical dysplasia. Epilepsia 56:1669-1686, 2015

38. Hader WJ, Tellez-Zenteno J, Metcalfe A, HernandezRonquillo L, Wiebe S, Kwon CS, et al: Complications of epilepsy surgery: a systematic review of focal surgical resections and invasive EEG monitoring. Epilepsia 54:840847,2013

39. Haglund MM, Berger MS, Shamseldin M, Lettich E, Ojemann GA: Cortical localization of temporal lobe language sites in patients with gliomas. Neurosurgery 34:567-576, 1994

40. Helmstaedter C, May TW, von Lehe M, Pfaefflin M, Ebner A, Pannek HW, et al: Temporal lobe surgery in Germany from 1988 to 2008: diverse trends in etiological subgroups. Eur J Neurol 21:827-834, 2014

41. Hu WH, Ge M, Zhang K, Meng FG, Zhang JG: Seizure outcome with surgical management of epileptogenic ganglioglioma: a study of 55 patients. Acta Neurochir (Wien) 154:855-861, 2012

42. Janszky J, Janszky I, Schulz R, Hoppe M, Behne F, Pannek $\mathrm{HW}$, et al: Temporal lobe epilepsy with hippocampal sclerosis: predictors for long-term surgical outcome. Brain 128:395-404, 2005

43. Jobst BC, Cascino GD: Resective epilepsy surgery for drugresistant focal epilepsy: a review. JAMA 313:285-293, 2015

44. Joo EY, Han HJ, Lee EK, Choi S, Jin JH, Kim JH, et al: Resection extent versus postoperative outcomes of seizure and memory in mesial temporal lobe epilepsy. Seizure 14:541-551, 2005

45. Jorge CL, Nagahashi-Marie SK, Pedreira CC, Rosemberg S, Valério RM, Valente KD, et al: Clinical characteristics and surgical outcome of patients with temporal lobe tumors and epilepsy. Arq Neuropsiquiatr 58:1002-1008, 2000

46. Kahlenberg CA, Fadul CE, Roberts DW, Thadani VM, Bujarski KA, Scott RC, et al: Seizure prognosis of patients with low-grade tumors. Seizure 21:540-545, 2012

47. Kaiboriboon K, Malkhachroum AM, Zrik A, Daif A, Schiltz NM, Labiner DM, et al: Epilepsy surgery in the United States: Analysis of data from the National Association of Epilepsy Centers. Epilepsy Res 116:105-109, 2015

48. Kirkpatrick PJ, Honavar M, Janota I, Polkey CE: Control of temporal lobe epilepsy following en bloc resection of lowgrade tumors. J Neurosurg 78:19-25, 1993 
49. Kral T, von Lehe M, Podlogar M, Clusmann H, Süssmann P, Kurthen M, et al: Focal cortical dysplasia: long term seizure outcome after surgical treatment. J Neurol Neurosurg Psychiatry 78:853-856, 2007

50. Krsek P, Maton B, Jayakar P, Dean P, Korman B, Rey G, et al: Incomplete resection of focal cortical dysplasia is the main predictor of poor postsurgical outcome. Neurology 72:217-223, 2009

51. Kurwale NS, Chandra SP, Chouksey P, Arora A, Garg A, Sarkar C, et al: Impact of intraoperative MRI on outcomes in epilepsy surgery: preliminary experience of two years. Br J Neurosurg 29:380-385, 2015

52. Kuzniecky R, Ho SS, Martin R, Faught E, Morawetz R, Palmer C, et al: Temporal lobe developmental malformations and hippocampal sclerosis: epilepsy surgical outcome. Neurology 52:479-484, 1999

53. Luyken C, Blümcke I, Fimmers R, Urbach H, Elger CE, Wiestler OD, et al: The spectrum of long-term epilepsyassociated tumors: long-term seizure and tumor outcome and neurosurgical aspects. Epilepsia 44:822-830, 2003

54. Manji H, Plant GT: Epilepsy surgery, visual fields, and driving: a study of the visual field criteria for driving in patients after temporal lobe epilepsy surgery with a comparison of Goldmann and Esterman perimetry. J Neurol Neurosurg Psychiatry 68:80-82, 2000

55. Neuloh G, Pechstein U, Cedzich C, Schramm J: Motor evoked potential monitoring with supratentorial surgery. Neurosurgery 61 (1 Suppl):337-348, 2007

56. Nimsky C, Ganslandt O, Buchfelder M, Fahlbusch R: Glioma surgery evaluated by intraoperative low-field magnetic resonance imaging. Acta Neurochir Suppl 85:55-63, 2003

57. Nimsky C, Ganslandt O, Von Keller B, Romstöck J, Fahlbusch R: Intraoperative high-field-strength MR imaging: implementation and experience in 200 patients. Radiology 233:67-78, 2004

58. Paglioli E, Palmini A, Portuguez M, Paglioli E, Azambuja N, da Costa JC, et al: Seizure and memory outcome following temporal lobe surgery: selective compared with nonselective approaches for hippocampal sclerosis. J Neurosurg 104:7078, 2006

59. Palmini A, Andermann F, Olivier A, Tampieri D, Robitaille $\mathrm{Y}$, Andermann E, et al: Focal neuronal migration disorders and intractable partial epilepsy: a study of 30 patients. Ann Neurol 30:741-749, 1991

60. Roessler K, Sommer B, Grummich P, Coras R, Kasper BS, Hamer HM, et al: Improved resection in lesional temporal lobe epilepsy surgery using neuronavigation and intraoperative MR imaging: favourable long term surgical and seizure outcome in 88 consecutive cases. Seizure 23:201-207, 2014

61. Rössler K, Sommer B, Grummich P, Hamer HM, Pauli E, Coras R, et al: Risk reduction in dominant temporal lobe epilepsy surgery combining fMRI/DTI maps, neuronavigation and intraoperative 1.5-Tesla MRI. Stereotact Funct Neurosurg 93:168-177, 2015

62. Rowland NC, Englot DJ, Cage TA, Sughrue ME, Barbaro NM, Chang EF: A meta-analysis of predictors of seizure freedom in the surgical management of focal cortical dysplasia. J Neurosurg 116:1035-1041, 2012

63. Ruban D, Byrne RW, Kanner A, Smith M, Cochran EJ, Roh D, et al: Chronic epilepsy associated with temporal tumors: long-term surgical outcome. Neurosurg Focus 27(2):E6, 2009

64. Rydenhag B, Flink R, Malmgren K: Surgical outcomes in patients with epileptogenic tumours and cavernomas in Sweden: good seizure control but late referrals. J Neurol Neurosurg Psychiatry 84:49-53, 2013

65. Salanova V, Markand O, Worth R: Temporal lobe epilepsy surgery: outcome, complications, and late mortality rate in 215 patients. Epilepsia 43:170-174, 2002
66. Sawrie SM, Martin RC, Kuzniecky R, Faught E, Morawetz $\mathrm{R}$, Jamil F, et al: Subjective versus objective memory change after temporal lobe epilepsy surgery. Neurology 53:15111517, 1999

67. Schramm J: Temporal lobe epilepsy surgery and the quest for optimal extent of resection: a review. Epilepsia 49:12961307, 2008

68. Schramm J, Lehmann TN, Zentner J, Mueller CA, Scorzin J, Fimmers R, et al: Randomized controlled trial of $2.5-\mathrm{cm}$ versus $3.5-\mathrm{cm}$ mesial temporal resection-Part 2: volumetric resection extent and subgroup analyses. Acta Neurochir (Wien) 153:221-228, 2011

69. Schramm J, Lehmann TN, Zentner J, Mueller CA, Scorzin $\mathrm{J}$, Fimmers R, et al: Randomized controlled trial of $2.5-\mathrm{cm}$ versus $3.5-\mathrm{cm}$ mesial temporal resection in temporal lobe epilepsy-Part 1: intent-to-treat analysis. Acta Neurochir (Wien) 153:209-219, 2011

70. Schwartz TH, Marks D, Pak J, Hill J, Mandelbaum DE, Holodny AI, et al: Standardization of amygdalohippocampectomy with intraoperative magnetic resonance imaging: preliminary experience. Epilepsia 43:430-436, 2002

71. Simon MV, Cole AJ, Chang EC, Buchbinder BR, Stufflebeam SM, Nozari A, et al: An intraoperative multimodal neurophysiologic approach to successful resection of precentral gyrus epileptogenic lesions. Epilepsia 53:e75-e79, 2012

72. Sommer B, Grummich P, Coras R, Kasper BS, Blumcke I, Hamer HM, et al: Integration of functional neuronavigation and intraoperative MRI in surgery for drug-resistant extratemporal epilepsy close to eloquent brain areas. Neurosurg Focus 34(4):E4, 2013

73. Sommer B, Grummich P, Hamer H, Bluemcke I, Coras R, Buchfelder M, et al: Frameless stereotactic functional neuronavigation combined with intraoperative magnetic resonance imaging as a strategy in highly eloquent located tumors causing epilepsy. Stereotact Funct Neurosurg 92:59-67, 2014

74. Sommer B, Kasper BS, Coras R, Blumcke I, Hamer HM, Buchfelder M, et al: Surgical management of epilepsy due to cerebral cavernomas using neuronavigation and intraoperative MR imaging. Neurol Res 35:1076-1083, 2013

75. Sommer B, Wimmer C, Coras R, Blumcke I, Lorber B, Hamer HM, et al: Resection of cerebral gangliogliomas causing drug-resistant epilepsy: short- and long-term outcomes using intraoperative MRI and neuronavigation. Neurosurg Focus 38(1):E5, 2015

76. Stefan H: Pathophysiology of human epilepsy: imaging and physiologic studies. Curr Opin Neurol 13:177-181, 2000

77. Stefan H, Hopp P, Platsch G, Kuwert T: SPECT: ictal perfusion in localization-related epilepsies. Adv Neurol 83:41-50, 2000

78. Stefan H, Hummel C, Hopfengärtner R, Pauli E, Tilz $\mathrm{C}$, Ganslandt O, et al: Magnetoencephalography in extratemporal epilepsy. J Clin Neurophysiol 17:190-200, 2000

79. Steinmeier R, Fahlbusch R, Ganslandt O, Nimsky C, Buchfelder M, Kaus M, et al: Intraoperative magnetic resonance imaging with the Magnetom open scanner: concepts, neurosurgical indications, and procedures: a preliminary report. Neurosurgery 43:739-748, 1998

80. Sun XY, Yu F: Microsurgical resection of a cavernous angioma that involves the optic pathway using a pterional approach: a case report and literature review. $\mathbf{B r} \mathbf{~ J}$ Neurosurg 26:882-885, 2012

81. Thom M, Blümcke I, Aronica E: Long-term epilepsyassociated tumors. Brain Pathol 22:350-379, 2012

82. Urbach H, Binder D, von Lehe M, Podlogar M, Bien CG, Becker A, et al: Correlation of MRI and histopathology in 
epileptogenic parietal and occipital lobe lesions. Seizure 16:608-614, 2007

83. Urbach H, Mast H, Egger K, Mader I, Presurgical MR imaging in epilepsy. Clin Neuroradiol 25 (Suppl 2):151155,2015

84. Van Gompel JJ, Marsh WR, Meyer FB, Worrell GA: Patientassessed satisfaction and outcome after microsurgical resection of cavernomas causing epilepsy. Neurosurg Focus 29(3):E16, 2010

85. Walker DG, Talos F, Bromfield EB, Black PM: Intraoperative magnetic resonance for the surgical treatment of lesions producing seizures. J Clin Neurosci 9:515-520, 2002

86. Wrench J, Wilson SJ, Bladin PF: Mood disturbance before and after seizure surgery: a comparison of temporal and extratemporal resections. Epilepsia 45:534-543, 2004

87. Yeon JY, Kim JS, Choi SJ, Seo DW, Hong SB, Hong SC: Supratentorial cavernous angiomas presenting with seizures: surgical outcomes in 60 consecutive patients. Seizure 18:1420,2009

88. Zevgaridis D, van Velthoven V, Ebeling U, Reulen HJ: Seizure control following surgery in supratentorial cavernous malformations: a retrospective study in 77 patients. Acta Neurochir (Wien) 138:672-677, 1996

\section{Disclosures}

The authors report no conflict of interest concerning the materials or methods used in this study or the findings specified in this paper.

\section{Author Contributions}

Conception and design: Roessler. Acquisition of data: all authors. Analysis and interpretation of data: Roessler, Hofmann, Sommer. Drafting the article: Roessler. Critically revising the article: Roessler, Sommer, Coras, Kasper, Hamer, Blumcke, Stefan, Nimsky, Buchfelder. Approved the final version of the manuscript on behalf of all authors: Roessler. Statistical analysis: Hofmann, Sommer. Study supervision: Roessler.

\section{Correspondence}

Karl Roessler, Department of Neurosurgery, University Hospital Erlangen, Schwabachanlage 6, Erlangen 91054, Germany. email: karl.roessler@uk-erlangen.de. 